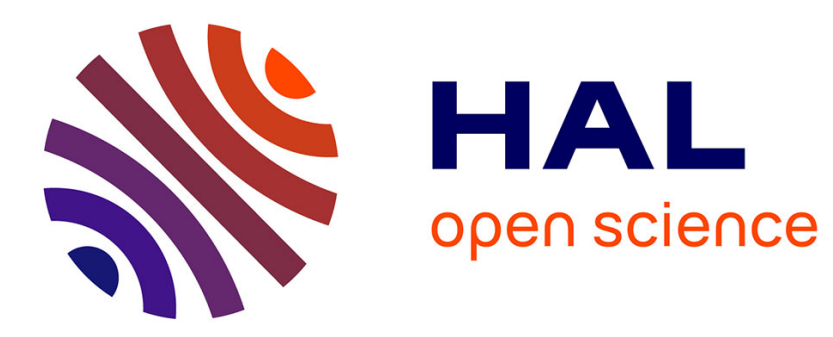

\title{
Effect of temperature on the synthesis of nanoporous carbon from copper/carbon thin films to nanoporous carbon for sensing applications
}

Laëtitia Donero, Nicolas Bouts, Abdel-Aziz El Mel, Brice Le Borgne, Eric Gautron, Laurent Le Brizoual, France Le Bihan, Pierre-Yves Tessier

\section{To cite this version:}

Laëtitia Donero, Nicolas Bouts, Abdel-Aziz El Mel, Brice Le Borgne, Eric Gautron, et al.. Effect of temperature on the synthesis of nanoporous carbon from copper/carbon thin films to nanoporous carbon for sensing applications. Thin Solid Films, 2017, 630, pp.59-65. 10.1016/j.tsf.2016.10.014 . hal-01518057

\section{HAL Id: hal-01518057 \\ https://hal.science/hal-01518057}

Submitted on 4 May 2017

HAL is a multi-disciplinary open access archive for the deposit and dissemination of scientific research documents, whether they are published or not. The documents may come from teaching and research institutions in France or abroad, or from public or private research centers.
L'archive ouverte pluridisciplinaire $\mathbf{H A L}$, est destinée au dépôt et à la diffusion de documents scientifiques de niveau recherche, publiés ou non, émanant des établissements d'enseignement et de recherche français ou étrangers, des laboratoires publics ou privés. 
Effect of temperature on the synthesis of nanoporous carbon from copper/carbon thin films to nanoporous carbon for sensing applications

L. Donero ${ }^{1,2}$, N. Bouts ${ }^{1}$, A. A. El Mel ${ }^{1}$, B. Le Borgne ${ }^{2}$, E. Gautron ${ }^{1}$, L. Le Brizoual ${ }^{2}$, F. Le Bihan $^{2}$, and P. Y. Tessier ${ }^{1}$

${ }^{1}$ Institut des Matériaux Jean Rouxel (IMN), Université de Nantes, CNRS, 2 rue de la Houssinière, B.P. 32229, 44322 Nantes Cedex 3, France

${ }^{2}$ Institut d'Electronique et de Télécommunication de Rennes (IETR), Université de Rennes 1, Campus de Beaulieu, 263 Avenue du Général Leclerc CS 7420535042 Rennes Cedex, France

\begin{abstract}
Over the last few years, a broad panel of carbon materials was proposed for sensing applications. Among these materials, nanoporous carbon (np-C) is of particular interest due to its high specific surface area and low fabrication cost. In this contribution, the synthesis of np$\mathrm{C}$ thin films using an approach combining the growth of copper/carbon nanocomposite thin films by co-sputtering followed by a selective wet etching of copper in nitric acid is studied. By adjusting the deposition conditions (e.g., powers applied to the sputtering targets, deposition temperature) of the nanocomposite thin films, it is shown that the pore size and the structure of the carbon skeleton can be modified. Furthermore, the possibility of integrating such nanoporous materials in field effect transistors for sensing application is also demonstrated.
\end{abstract}

Keywords: Nanoporous; carbon; copper; nanocomposite thin films; sputtering; etching 


\section{Introduction}

Nanoporous carbon (np-C) is an appealing material for a broad range of practical applications in various research fields including catalysis [1], biosensing [2], energy storage (supercapacitors) [3], filtration and purification of gas and liquids [3, 4]). The interest toward this class of material arises from their good mechanical stability [3], and high active specific surface area [5]. These properties can be modulated by adjusting the characteristics (e.g., size, shape and density) of the nanopores [6].

Enormous efforts have been dedicated lately to the development of novel techniques allowing synthesizing nanoporous materials with adjustable properties, $[7,8]$ including wet-chemical and electrochemical routes [9], template approaches [10], chemical vapor deposition [5,11], pyrolysis of organic polymer precursors [3] and low-energy cluster beam deposition [11]. Recently, our group has developed a two-step approach to synthesize np-C thin films [6]. The process consists in the deposition of copper/carbon nanocomposite $(\mathrm{nc}-\mathrm{Cu} / \mathrm{C})$ thin films followed by a selective chemical etching of the copper phase in order to obtain np-C.

Metal/carbon nanocomposites (nc-Me/C) can be described as heterogeneous materials consisting of metal or metal rich nanoparticles embedded in a carbon film matrix. This kind of material has been widely studied during the last two decades, mainly for coating applications [12]. Different systems have been explored, including Ni [13], Fe [14], Cu [15,16], Au and Pt

[14]. Our nc-Cu/C thin films were synthesized by co-sputtering of a graphite and a copper target in co-focal configuration at low temperature [6]. We have made clear that it was possible to control the size and density of the obtained nanopores by adjusting the $\mathrm{nc}-\mathrm{Cu} / \mathrm{C}$ sputtering conditions. We also showed that the electrical conductivity of the obtained np-C was dependent on its microstructure and morphology [6]. Nevertheless, our study was limited to the synthesis of nc-Cu/C films deposited at low temperature (i.e. no intentional heating was applied to the substrate during the deposition). The deposition temperature can drastically 
impact the morphology and the microstructures of such nanocomposite materials. For example, in the case of nc-Ni/C thin films, an increase of the deposition temperature leads to a strong modification in film morphology and structure due to the self-organization of the metal within the carbon matrix during the growth [17].

In case of the $\mathrm{nc}-\mathrm{Cu} / \mathrm{C}$ films, the deposition temperature can also strongly modify the morphology of the obtained nc-Me/C material, and thus the one of the $\mathrm{np}-\mathrm{C}$ formed after nitric acid etching. The aim of this paper is to evaluate the impact of the deposition temperature on the morphology/structure of $\mathrm{nc}-\mathrm{Cu} / \mathrm{C}$ thin films and the consequence on the formation of the np-C thin films.

\section{Experimental section}

The $\mathrm{nc}-\mathrm{Cu} / \mathrm{C}$ thin films were synthesized using a co-sputtering process [6]. The film depositions were performed on thermally oxidized silicon substrates $(500 \mathrm{~nm} \mathrm{SiO} 2)$. A copper and a graphite target mounted on DC magnetron sources in co-focal configuration were used. The deposition pressure was fixed to $0.5 \mathrm{~Pa}$. The chemical composition of the films was adjusted by tuning the electrical powers applied to the targets. The electrical power applied to the graphite target was fixed to $100 \mathrm{~W}$. In order to change the copper content in the $\mathrm{nc}-\mathrm{Cu} / \mathrm{C}$ thin films, four electrical powers were applied to the copper target: $\mathrm{P}_{\mathrm{Cu}}=25 \mathrm{~W}, 50 \mathrm{~W}, 75 \mathrm{~W}$ and $100 \mathrm{~W}$. Four deposition temperatures were also tested: room temperature (RT - no intentional heating), 400, 500 and $600{ }^{\circ} \mathrm{C}$. During the deposition, the substrate rotation speed was $5 \mathrm{rpm}$. The deposition time at room temperature was adjusted in order to obtain thin films with a mean thickness around $500 \mathrm{~nm}$. The chemical composition of the films was evaluated using energy dispersive X-ray spectroscopy (EDS) with JEOL 5800 operating at $5 \mathrm{kV}$. The crystalline structure of the films was probed using X-ray diffraction (XRD) with Moxtek D8 in a configuration Bragg-Brentano. The x-ray source is copper anode. The morphology was 
analyzed using scanning electron microscopy (SEM) with JEOL $7600 \mathrm{~F}$ microscope operating at $15 \mathrm{kV}$. Transmission electron microscopy (TEM) imaging of copper nanoparticles was carried out on a Hitachi H9000-NAR microscope operating at $300 \mathrm{kV}$ equipped with a $\mathrm{LaB}_{6}$ filament and exhibiting a point-to-point resolution of $0.18 \mathrm{~nm}$. To obtain nanoporous carbon, the $\mathrm{nc}-\mathrm{Cu} / \mathrm{C}$ thin films were exposed to concentrated nitric acid solution for $1 \mathrm{~min}$ (70 wt. \%, Sigma Aldrich). According to our previous work, to obtain nanoporous carbon using such an approach, the copper nanoparticles must be percolated otherwise the nitric acid cannot propagate within the material and selectively dissolve the copper phase. This can be easily identified by measuring the electrical conductivity of the films [6]. Based on our previous work, we have carefully selected the values of $\mathrm{P}_{\mathrm{Cu}}$ in such a way that the copper nanoparticles percolate within the carbon matrix. The structure of the carbon phase was probed using Raman spectroscopy carried out on a Renishaw in Via Raman microscope equipped with a $514 \mathrm{~nm}$ argon laser. To avoid any possible sample damage, the laser power was limited to 1.5 mW.

\section{Results and discussions}

\section{1. nc-Cu/C: effect of electrical power and substrate temperature}

Figure 1 shows the evolution of the $\mathrm{Cu} / \mathrm{C}$ atomic ratio as a function of the electrical power applied to the copper target deduced from EDS measurements for thin films deposited at room temperature. The $\mathrm{Cu} / \mathrm{C}$ ratio varies from 3.6 to 9 by adjusting the power applied to the copper target from 25 to $100 \mathrm{~W}$. Since we ensured the ability of the process to modify the chemical composition of the films, these four conditions were repeated at deposition temperatures of 400, 500 and $600{ }^{\circ} \mathrm{C}$. From the plan-view SEM micrographs (Figure 2) at RT (Figure 2 a-d), one can conclude that all the films exhibit a globular morphology which is the typical characteristic of $\mathrm{nc}-\mathrm{Cu} / \mathrm{C}$ films grown by magnetron sputtering [18-20]. No significant 
evolution of the morphology with $\mathrm{P}_{\mathrm{Cu}}$ can be seen. In the case of films deposited at $500{ }^{\circ} \mathrm{C}$, we observe a more porous structure when increasing $\mathrm{P}_{\mathrm{Cu}}$ (Figure $2 \mathrm{e}-\mathrm{h}$ ). This evolution is observed for all temperature conditions. The evolution of the deposition rate as a function of $\mathrm{P}_{\mathrm{Cu}}$ for all temperature conditions $\left(\mathrm{RT}, 400^{\circ} \mathrm{C}, 500^{\circ} \mathrm{C}\right.$ and $600^{\circ} \mathrm{C}$ ) is presented in figure 3 . The deposition rate is defined as the ratio of the apparent thickness to the deposition time. The apparent thickness is estimated from cross-sectional SEM micrographs. As expected, a linear increase of the deposition rate with $\mathrm{P}_{\mathrm{Cu}}$ is observed at $\mathrm{RT}$. The most surprising result is the increase of the deposition rate with the deposition temperature for a constant value of $\mathrm{P}_{\mathrm{Cu}}$. This effect becomes more pronounced for high values of $\mathrm{P}_{\mathrm{Cu}}$ which correspond to high content of copper within the films. For example, at $\mathrm{P}_{\mathrm{Cu}}=100 \mathrm{~W}$, the deposition rate increases by $84 \%$ from RT to $500^{\circ} \mathrm{C}$. Considering that the fluxes of the deposited sputtered species (carbon and copper atoms) depend only on the sputter deposition conditions (e.g. target powers) and are independent of the substrate temperature, we can conclude that this observed increase of the apparent deposition rate is a consequence of a strong increase of the porosity of the films with the deposition temperature. This conclusion is consistent with the morphology identified in the SEM images presented in figure 2 where an enhancement in the porosity is observed as a function of the deposition temperature at a constant power applied to the target. A study has shown that it is possible to obtain pure nanoporous copper directly by magnetron sputtering deposition at $570{ }^{\circ} \mathrm{C}$ [21]. This strong modification of morphology is attributed to a repeated nucleation growth on copper grains and an incomplete intergrowth which leads to a high porosity. In the case of $\mathrm{nc}-\mathrm{C} / \mathrm{Cu}$ films, the role of carbon could be questionable but we can notice that the increase of the deposition rate (fig. 3) with temperature is highly remarkable for film with high content of copper. This can be an indication that copper has the dominant role in the formation of porosity at relatively high deposition temperatures. In addition, carbon and copper are not soluble [22] and their 
behavior during the growth could be considered independently. Therefore, the explanation of this porosity probably comes from the presence of copper in copper rich composite thin films as such an effect was not observed for films with very low copper concentrations. The other effect which cannot be excluded is the local shadowing on surface which also can lead to an increase in the porosity. Indeed, the deposition process is a co-focal sputtering process with an incidence angle of $30^{\circ}$ of the magnetron axis on the rotating substrate surface.

It is interesting to investigate the influence of the temperature on the microstructure of the films. Figure 4a shows the XRD patterns recorded on $n c-C u / C$ films grown with $\mathrm{P}_{C u}=50 \mathrm{~W}$ and $100 \mathrm{~W}$ at $\mathrm{RT}$ and $\mathrm{P}_{\mathrm{Cu}}=50 \mathrm{~W}$ at $500^{\circ} \mathrm{C}$. Two different phases can be identified: face centered cubic (fcc) $\mathrm{Cu}$ and $\mathrm{fcc} \mathrm{Cu}_{2} \mathrm{O}$. The intensity of the (111) peak of the $\mathrm{Cu}$ phase is found to increase as increasing $\mathrm{P}_{\mathrm{Cu}}$ indicating an increase in the amount of crystalline $\mathrm{Cu}$ present within the films. Applying an intentional heating to the substrate during the film deposition results in the formation of a $\mathrm{Cu}_{2} \mathrm{O}$ phase within the film. The amount of $\mathrm{Cu}_{2} \mathrm{O}$ becomes more significant as increasing the deposition temperature from RT to $500{ }^{\circ} \mathrm{C}$. This is an indication that an oxidation process occurs in case of films deposited at high temperatures. Such an oxidation can take place during the growth of the films but this assumption is unlikely because of the low value of the residual pressure in the deposition chamber. The oxidation may also simply originate from the oxidation of copper due to the exposure of the films to the ambient atmosphere after deposition. In this last case, the presence of porosity in the as-grown films is expected to promote such an oxidation effect of the $\mathrm{Cu}$ nanoparticles.

After dispersion on a carbon coated TEM grid, the copper nanoparticles were observed by TEM for a sample deposited at $\mathrm{P}_{\mathrm{Cu}}=75 \mathrm{~W}$. The TEM images reveal spherical copper nanoparticles with a size ranging from few nanometers at RT to few tenth of nanometers at $600^{\circ} \mathrm{C}$ (Figure $\left.5 \mathrm{a}-\mathrm{d}\right)$. 
Using the XRD patterns, the crystallite size can be estimated using the Debye-Scherrer formula given by:

$$
t=\frac{\lambda}{\varepsilon} * \cos (\theta)
$$

where $\lambda(1.5406 \AA)$ is the wavelength of the used source, $\varepsilon$ and $\theta$ are respectively the full width at half maximum (FWHM) and the position of the (111) peak of $\mathrm{Cu}$. The evolution of the crystallite size as a function of the deposition temperature for films deposited with various values of $\mathrm{P}_{\mathrm{Cu}}$ are presented in figure $4 \mathrm{~b}$. The variation range in crystallite size is found to be dependent on $\mathrm{P}_{\mathrm{Cu}}$ : between 6 and $12 \mathrm{~nm}$ for $\mathrm{P}_{\mathrm{Cu}}$ of $25 \mathrm{~W}$, between 12 and $23 \mathrm{~nm}$ for $\mathrm{P}_{\mathrm{Cu}}=50$ $\mathrm{W}$, from15 to $30 \mathrm{~nm}$ for $\mathrm{P}_{\mathrm{Cu}}=75 \mathrm{~W}$ and between 19 and $29 \mathrm{~nm}$ for $\mathrm{P}_{\mathrm{Cu}}$ of $100 \mathrm{~W}$. This phenomenon has already been observed in the case of post-deposition annealing of $\mathrm{nc}-\mathrm{Cu} / \mathrm{C}$ films [23]. These results are consistent with the TEM observations of the copper nanoparticles.

\subsection{Nanoporous carbon: effect of power and temperature}

The chemical process used to obtain nanoporous carbon consists in immersing the $\mathrm{nc}-\mathrm{Cu} / \mathrm{C}$ thin film in concentrated nitric acid for 1 min followed by rinsing the samples in distilled water in order to stop the etching process and remove the reaction residues.

The cross-section and the plan-view SEM micrographs recorded on nc-Cu/C films grown at $400{ }^{\circ} \mathrm{C}$ with $\mathrm{P}_{\mathrm{Cu}}=50 \mathrm{~W}$ before and after etching are displayed in figure 6 a-d. After etching (Figure $6 \mathrm{c}$-d) a strong morphological change accompanied with a decrease in the thickness of the film can be observed. For example, in figure $6 \mathrm{~b}$-d, the etching process leads to a thickness decrease of $40 \%$. This change is probably due to the mechanical relaxation of the material occurring as a consequence to the removal of the $\mathrm{Cu}$ nanoparticles from the carbon matrix 
$[6,24]$. The EDS spectra recorded on these samples before and after etching (figure 6 e) confirm the complete removal of the copper phase after etching in nitric acid. The Raman analyses reveal a strong increase in the Raman signal after etching (figure $6 \mathrm{f}$ ). Copper should inhibit the Raman mode of the carbon phase before etching [6]. Removing copper would thus lead to an activation of these modes. On these Raman spectra, the well-known D (around $1370 \mathrm{~cm}-1$ ) and $\mathrm{G}$ peaks (around $1580 \mathrm{~cm}-1$ ) can be identified. Briefly, the D peak originates from the $\mathrm{sp}^{2}$ breathing mode of the carbon atoms arranged in aromatic rings, whereas the presence of the $\mathrm{G}$ peak is due to all the vibrations of the $\mathrm{sp}^{2}$ hybridized carbon atoms standing in the carbon phase $[23,25,26]$. From these two peaks, it is possible to extract different parameters allowing to access to the micro-organization of the carbon atoms forming the matrix. The $\mathrm{I}_{\mathrm{D}} / \mathrm{I}_{\mathrm{G}}$ ratio of the $\mathrm{G}$ and $\mathrm{D}$ peaks intensities provides information on the proportion of carbon atoms contribution to the formation of aromatic rings $[27,28]$. The $G$ peak position, Pos $(\mathrm{G})$, provides information on the topological order as well as on the organization of carbon materials. In the case of graphite, Pos (G) is $1600 \mathrm{~cm}^{-1}$ indicating that the carbon atoms are mainly organized in aromatic rings, and few carbon chains (olefin structures) are present [29]. The full width at half maximum of the G peak, FWHM (G), reflects the order (or disorder) in the spatial organization of carbon atoms. A decrease in FWHM indicated a low disorder. For example, in the case of graphite with well-ordered stack composed of single graphene sheets, FWHM $(\mathrm{G})$ is measured at $13 \mathrm{~cm}^{-1}$ for a wavelength of $514 \mathrm{~nm} \mathrm{[30].} \mathrm{To}$ extract these parameters, an optimized fitting method was applied: while the D peak was described using a classical Lorentzian shape a Breit- Wigner-Fano was preferred to describe the $G$ peak $[6,19,26,28]$.

To explore the effect of temperature on the growth of np-C, a systematic Raman study was performed for all conditions after etching. Figure 7 shows the evolution of the different Raman parameters (i.e. $\mathrm{I}_{\mathrm{D}} / \mathrm{I}_{\mathrm{G}}$ (figure $7 \mathrm{a}$ ), Pos $(\mathrm{G})$ (figure 7 b) and FWHM (G) (figure $7 \mathrm{c}$ ) for 
the different powers applied to the copper target and the different substrate temperatures.

An increase in $I_{D} / I_{G}$ ratio with the deposition temperature is observed (figure 7 a). It would thus indicate that aromatic rings organization is favored by an increase in the deposition temperature. A shift in the position of the $G$ peak is also observed when increasing the deposition temperature (Figure $7 b$ ). According to the literature $[23,25,26]$, such behavior confirms that increasing the deposition temperature leads to an increase in the proportion of carbon atoms arranged under aromatic rings. At last, the full width at half maximum is observed to decreases with increasing the deposition temperature for all conditions (Figure $7 d)$.

The Raman spectroscopy study can be summarized as follows: a better organization of carbon atoms can be reached for the higher deposition temperatures. Indeed, the copper nanoparticles present in the nc-Cu/C likely act as a catalyst for the crystallization of carbon [23].

Figure 8 shows SEM micrographs of np-C obtained from $\mathrm{nc}-\mathrm{Cu} / \mathrm{C}$ thin films deposited at room temperature and at $500^{\circ} \mathrm{C}$ for a power applied to the copper target ranging from $25 \mathrm{~W}$ to $75 \mathrm{~W}$. At room temperature, an increase in pore size with $\mathrm{P}_{\mathrm{Cu}}$ is observed (Figure $8 \mathrm{a}-\mathrm{c}$ ). This trend has already been observed in our previous work and is discussed in [6]. For np-Cs obtained from thin films deposited at $500^{\circ} \mathrm{C}$, the same trend is observed (Figure $8 \mathrm{~d}-\mathrm{f}$ ). The comparison of the obtained morphologies allows concluding that increasing the $\mathrm{nc}-\mathrm{Cu} / \mathrm{C}$ deposition temperature leads to an increase in the final pore size within np-C. The same evolution was also remarked for all the considered deposition conditions.

This change in pore size with the temperature is consistent with the change in nanoparticles size observed by SEM, TEM and XRD (figures 2, 4 and 5). From high magnification SEM micrographs, it is possible to evaluate the mean size of the pores. Figure 9 shows the evolution of the pore size with the synthesis temperature for the different values of $\mathrm{P}_{\mathrm{Cu}}$. For thin films deposited with a power applied to the copper target $\mathrm{P}_{\mathrm{Cu}}=25 \mathrm{~W}$, an increase of the 
pore size from $\sim 7$ to $\sim 8 \mathrm{~nm}$ is observed when increasing the deposition temperature from RT to $600{ }^{\circ} \mathrm{C}$. For $\mathrm{P}_{\mathrm{Cu}}=50 \mathrm{~W}$, an increase in pore size from $\sim 9$ to $\sim 12 \mathrm{~nm}$ can be remarked. For $\mathrm{P}_{\mathrm{Cu}}=75 \mathrm{~W}$, the pore size increase from $\sim 9$ to $\sim 18 \mathrm{~nm}$. For $\mathrm{P}_{\mathrm{Cu}}=100 \mathrm{~W}$ and for deposition temperature higher than the room temperature, due to the high proportion of copper in films, a partial film delamination was observed after dealloying, making the cross sectional SEM observation not possible.

The pore size increases with the $\mathrm{nc}-\mathrm{Cu} / \mathrm{C}$ deposition temperature. It is thus possible to control the pore size by simply adjusting the deposition parameters of $\mathrm{nc}-\mathrm{Cu} / \mathrm{C}$ thin films. By comparing the pore size evaluated from SEM micrographs and the crystallite size estimated from $\mathrm{XRD}$, it can be noticed that, the pore size is smaller than the one of the copper crystallites. This evolution is consistent with the decrease in thickness observed after etching, and probably indicates a mechanical relaxation of the film during copper removal.

\section{Demonstration of the integration of $\mathrm{np}-\mathrm{C}$ in a MOSFET sensor}

Since many years, MOSFET sensors have been studied for applications of detection $(\mathrm{pH}$, DNA, protein...) [31-34]. The goal of this part is to demonstrate that the relatively low temperature process that we have developed in this study to synthesize $\mathrm{np}-\mathrm{C}$ thin films is fully compatible with the integration of such a functional material on the active surface of a Metal Oxide Field Effect Transistor (MOSFET) sensor.

The studied device consists of a bottom gate field effect transistor with an active layer which can be functionalized with various nanostructures. Figure 10 presents a layout image of the device. The integration of the porous carbon allows increasing the active specific surface area and thus allows increasing the sensor sensitivity for the detection of bio-chemical species.

A thin layer of $\mathrm{nc}-\mathrm{Cu} / \mathrm{C}$ with $\mathrm{P}_{\mathrm{Cu}}=50 \mathrm{~W}$ at $400{ }^{\circ} \mathrm{C}$ was deposited only on the active area by lift off. The porous carbon was obtained after an etching step in nitric acid for $1 \mathrm{~min}$. A SEM 
image recorded on the MOSFET surface confirms the presence of a well localized film between the drain and the source electrode (figure $11 \mathrm{a}$ ). Figure $11 \mathrm{~b}$ shows the morphology of the nanoporous carbon obtained in the active area of the MOSFET sensor. Figure 11c shows the electrical measurements before and after integration of nanoporous carbon on the active surface of the device. The transfer characteristics of the MOSFET with nanoporous carbon show no degradation of the field effect in on-state but an increase in the off-current. This result proves that the np-C synthesis is fully compatible with the standard fabrication processes of MOSFET devices. One can notice a shift in the transfer characteristic after the integration of the $\mathrm{np}-\mathrm{C}$ thin film in figure $10 \mathrm{c}$. This shift confirms the influence of the upper surface on the electrical characteristics.

\section{Conclusion}

Deposition of $\mathrm{nc}-\mathrm{Cu} / \mathrm{C}$ thin films followed by a chemical etching of copper is a very simple method to synthesize nanoporous carbon films. The initial concentration of copper in the nc$\mathrm{Cu} / \mathrm{C}$ film (controlled by the power applied to the sputtering targets) and the deposition temperature are two interesting deposition parameters which allow controlling the final porosity of the np-C films and the nature of the carbon microstructure. Moreover, the relatively low temperature used to synthesize np-C films opens the way to a deposition of these films on various fragile substrates or active surface of sensors. In this study, the np-C integration in a MOSFET sensor without affecting the electrical characteristics has been demonstrated. This first result is promising for FET based sensors technologies requiring carbon electrode with a highly active specific surface area. 
[1] J. Wang, Q. Chen, C.L. Renschler, C. White, Ultrathin Porous Carbon Films as Amperometric Transducers for Biocatalytic Sensors, Anal. Chem. 66 (1994) 1988-1992.

[2] K. Mondal, M.A. Ali, S. Srivastava, B.D. Malhotra, A. Sharma, Electrospun functional micro/nanochannels embedded in porous carbon electrodes for microfluidic biosensing, Sensors and Actuators B: Chemical. 229 (2016) 82-91.

[3] Y. Tao, M. Endo, M. Inagaki, K. Kaneko, Recent progress in the synthesis and applications of nanoporous carbon films, J. Mater. Chem. 21 (2011) 313-323.

[4] H. Hatori, H. Takagi, Y. Yamada, Gas separation properties of molecular sieving carbon membranes with nanopore channels, Carbon. 42 (2004) 1169-1173.

[5] W. Dai, S.J. Kim, W.-K. Seong, S.H. Kim, K.-R. Lee, H.-Y. Kim, M.-W. Moon, Porous Carbon Nanoparticle Networks with Tunable Absorbability, Scientific Reports. 3 (2013).

[6] N. Bouts, A.-A. El Mel, B. Angleraud, P.-Y. Tessier, Sponge-like carbon thin films: The dealloying concept applied to copper/carbon nanocomposite, Carbon. 83 (2015) 250-261.

[7] Y. Gogotsi, A. Nikitin, H. Ye, W. Zhou, J.E. Fischer, B. Yi, H.C. Foley, M.W. Barsoum, Nanoporous carbide-derived carbon with tunable pore size, Nat Mater. 2 (2003) 591-594.

[8] P. Krawiec, E. Kockrick, L. Borchardt, D. Geiger, A. Corma, S. Kaskel, Ordered Mesoporous Carbide Derived Carbons: Novel Materials for Catalysis and Adsorption, J. Phys. Chem. C. 113 (2009) 7755-7761.

[9] A. Chauvin, C. Delacôte, L. Molina-Luna, M. Duerrschnabel, M. Boujtita, D. Thiry, K. Du, J. Ding, C.-H. Choi, P.-Y. Tessier, A.-A. El Mel, Planar Arrays of Nanoporous Gold Nanowires: When Electrochemical Dealloying Meets Nanopatterning, ACS Appl. Mater. Interfaces. 8 (2016) 6611-6620.

[10] L. Chuenchom, R. Kraehnert, B.M. Smarsly, Recent progress in soft-templating of porous carbon materials, Soft Matter. 8 (020812) 10801-10812.

[11] G. Bongiorno, A. Podestà, L. Ravagnan, P. Piseri, P. Milani, C. Lenardi, S. Miglio, M. Bruzzi, C. Ducati, Electronic properties and applications of cluster-assembled carbon films, J Mater Sci: Mater Electron. 17 (2006) 427-441.

[12] P.B. Barna, M. Adamik, J. Lábár, L. Kövér, J. Tóth, A. Dévényi, R. Manaila, Formation of polycrystalline and microcrystalline composite thin films by codeposition and surface chemical reaction, Surface and Coatings Technology. 125 (2000) 147-150.

[13] G.J. Kovács, G. Sáfrán, O. Geszti, T. Ujvári, I. Bertóti, G. Radnóczi, Structure and mechanical properties of carbon-nickel and CNx-nickel nanocomposite films, Surface and Coatings Technology. 180-181 (2004) 331-334.

[14] K.I. Schiffmann, M. Fryda, G. Goerigk, R. Lauer, P. Hinze, A. Bulack, Sizes and distances of metal clusters in $\mathrm{Au}$-, $\mathrm{Pt}$-, $\mathrm{W}$ - and Fe-containing diamond-like carbon hard coatings: a comparative 
study by small angle $\mathrm{X}$-ray scattering, wide angle $\mathrm{X}$-ray diffraction, transmission electron microscopy and scanning tunnelling microscopy, Thin Solid Films. 347 (1999) 60-71.

[15] C.-C. Chen, F.C.-N. Hong, Structure and properties of diamond-like carbon nanocomposite films containing copper nanoparticles, Applied Surface Science. 242 (2005) 261-269.

[16] L. Huang, H. Jiang, J. Zhang, Z. Zhang, P. Zhang, Synthesis of copper nanoparticles containing diamond-like carbon films by electrochemical method, Electrochemistry Communications. 8 (2006) 262-266.

[17] G. Abrasonis,Gy. J. Kovács, L. Ryves, M. Krause, A. Mücklich, F. Munnik, T. W. H. Oates, M. M. M. Bilek, and W. Möller, Phase separation in carbon-nickel films during hyperthermal ion deposition, Journal of Applied Physics 105 (2009), 083518.

[18] M.-Y. Tsai, M.-S. Huang, L.-K. Chen, Y.-D. Shen, M.-H. Lin, Y.-C. Chiang, K.-L. Ou, S.-F. Ou, Surface properties of copper-incorporated diamond-like carbon films deposited by hybrid magnetron sputtering, Ceramics International. 39 (2013) 8335-8340.

[19] A.A. Onoprienko, N.I. Danilenko, I.A. Kossko, Structure evolution on annealing of copperdoped carbon film, Thin Solid Films. 515 (2007) 6672-6675.

[20] P. Guo, L. Sun, X. Li, S. Xu, P. Ke, A. Wang, Structural properties and surface wettability of Cucontaining diamond-like carbon films prepared by a hybrid linear ion beam deposition technique, Thin Solid Films. 584 (2015) 289-293.

[21] V.I. Perekrestov, Y.O. Kosminska, A.S. Kornyushchenko, V.M. Latyshev, Self-assembly of porous $\mathrm{Cu}$ structures during steady-state condensation of weakly supersaturated vapors, J Porous Mater. 21 (2014) 1159-1167.

[22] G.A. López, E.J. Mittemeijer, The solubility of C in solid Cu, Scripta Materialia. 51 (2004) 1-5.

[23] M. Berndt, M. Krause, G. Abrasonis, A. Mücklich, F. Munnik, A. Kolitsch, W. Möller, Morphology and Structure of C:Co, C:V, and C:Cu Nanocomposite Films, Plasma Processes Polym. 6 (2009) S902-S906.

[24] A.-A. El Mel, F. Boukli-Hacene, L. Molina-Luna, N. Bouts, A. Chauvin, D. Thiry, E. Gautron, N. Gautier, P.-Y. Tessier, Unusual Dealloying Effect in Gold/Copper Alloy Thin Films: The Role of Defects and Column Boundaries in the Formation of Nanoporous Gold, ACS Appl. Mater. Interfaces. 7 (2015) 2310-2321.

[25] C. Casiraghi, F. Piazza, A.C. Ferrari, D. Grambole, J. Robertson, Bonding in hydrogenated diamond-like carbon by Raman spectroscopy, Diamond and Related Materials. 14 (2005) 1098-1102.

[26] M. Berndt, G. Abrasonis, G.J. Kovács, M. Krause, F. Munnik, R. Heller, A. Kolitsch, W. Möller, Bulk diffusion induced structural modifications of carbon-transition metal nanocomposite films, Journal of Applied Physics. 109 (2011) 63503. 
[27] J. Robertson, Diamond-like amorphous carbon, Materials Science and Engineering: R: Reports. 37 (2002) 129-281.

[28] A.C. Ferrari, J. Robertson, Interpretation of Raman spectra of disordered and amorphous carbon, Phys. Rev. B. 61 (2000) 14095-14107.

[29] A.C. Ferrari, J. Robertson, Resonant Raman spectroscopy of disordered, amorphous, and diamondlike carbon, Phys. Rev. B. 64 (2001) 75414.

[30] A.C. Ferrari, Raman spectroscopy of graphene and graphite: Disorder, electron-phonon coupling, doping and nonadiabatic effects, Solid State Communications. 143 (270307) 47-57.

[31] M.S. Makowski, A. Ivanisevic, Molecular Analysis of Blood with Micro-/Nanoscale Field-EffectTransistor Biosensors, Small. 7 (2011) 1863-1875.

[32] A. Kherrat, F.L. Bihan, F. Razan, N. Coulon, L. Griscom, O.D. Sagazan, S. Crand, T. MohammedBrahim, pH Micro-Sensors Associated with Micro-Fluidics for Chemical Analysis, ECS Trans. 33 (2010) 153-159.

[33] A. Kherrat, F. Le Bihan, F. Razan, E. Jacques, M. Thomas, O. De Sagazan, S. Crand, T. Mohammed-Brahim, pH sensing from frequency response of SGFET, in: IEEE SENSORS 2011 Conference, Limerick, Ireland, 2011.

[34] I. Bouhadda, O. de sagazan, F. Le Bihan, Suspended Gate Field Effect Transistor with an Integrated Micro-Fluidic Channel Performed by Surface Micromachining for Liquids Sensing, Procedia Engineering. 47 (2012) 754-757. 


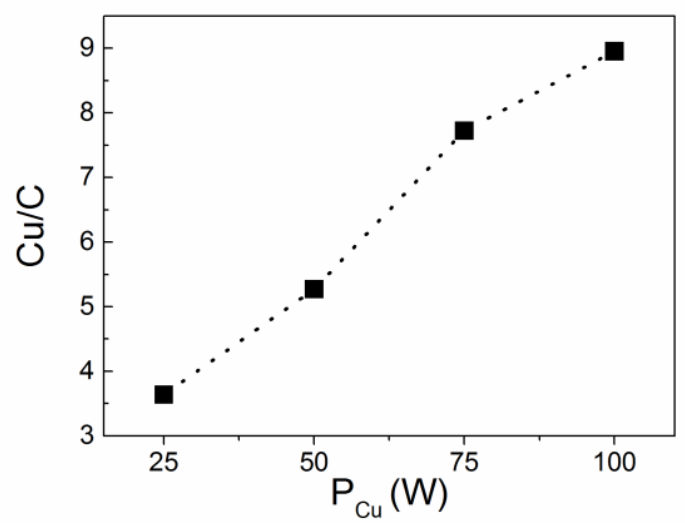

Figure 1: Evolution of the composition of $\mathrm{nc}-\mathrm{Cu} / \mathrm{C}$ films as a function of the electrical power, $\mathrm{P}_{\mathrm{Cu}}$, applied to the copper target. 

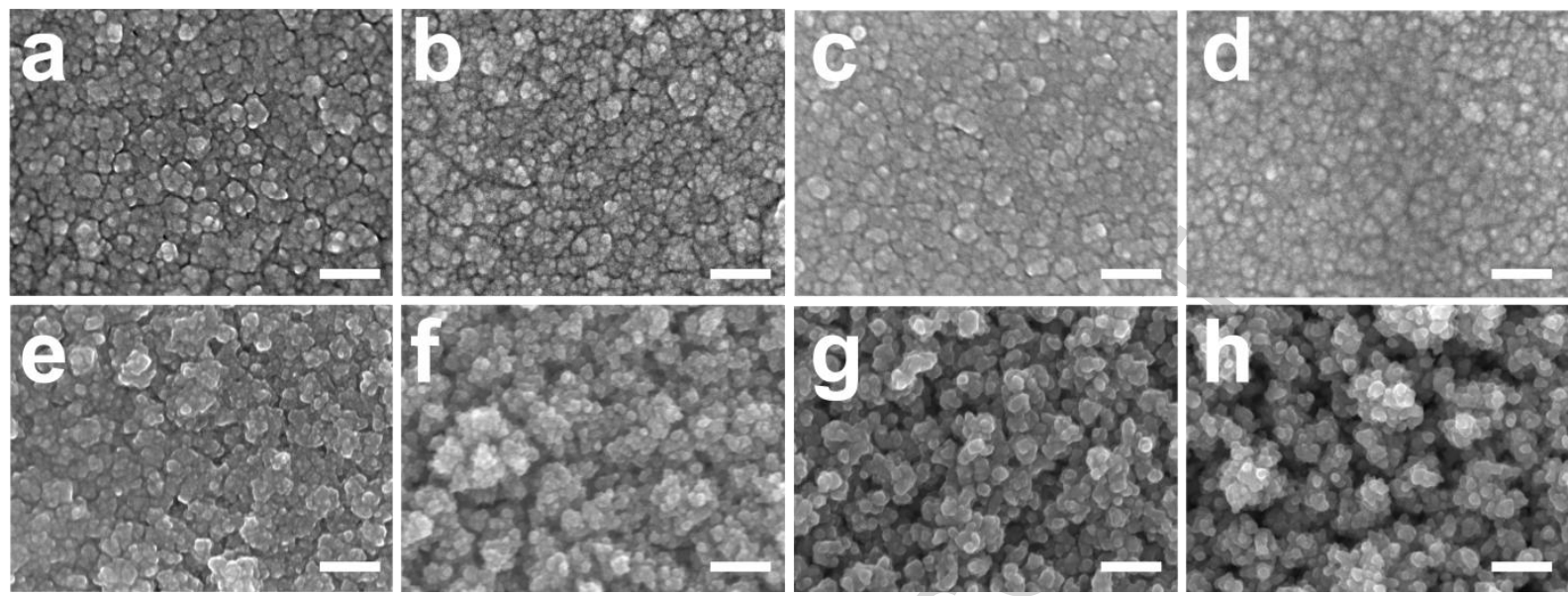

Figure 2: Top-view SEM micrographs of nc-Cu/C thin film grown at room temperature (a-d) and at $500{ }^{\circ} \mathrm{C}(\mathrm{e}-\mathrm{h})$ with different values of $\mathrm{P}_{\mathrm{Cu}}$ : $25 \mathrm{~W}$ (a and e), $50 \mathrm{~W}$ (b and f), $75 \mathrm{~W}$ (c and g) and $100 \mathrm{~W}(\mathrm{~d}$ and $\mathrm{h})$ - (Scale bar $100 \mathrm{~nm})$. 


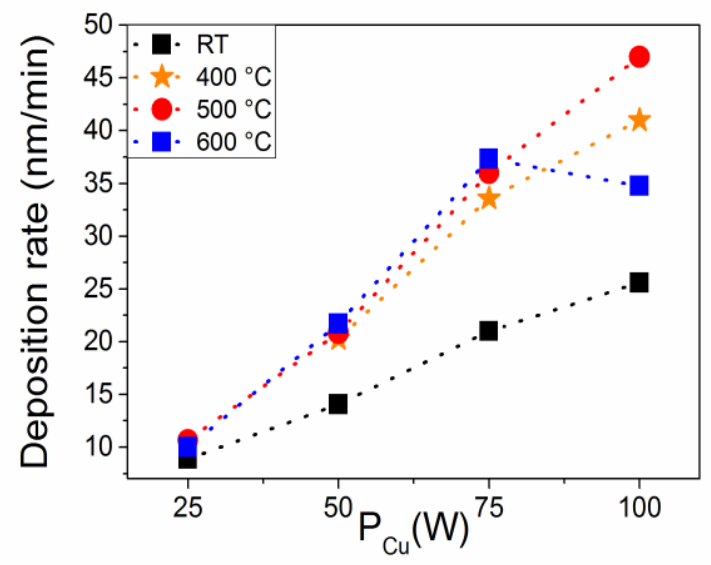

Figure 3: Evolution of the deposition rate of nc-Cu/C films at different substrate temperatures as a function of the electrical power, $\mathrm{P}_{\mathrm{Cu}}$, applied to the copper target. 

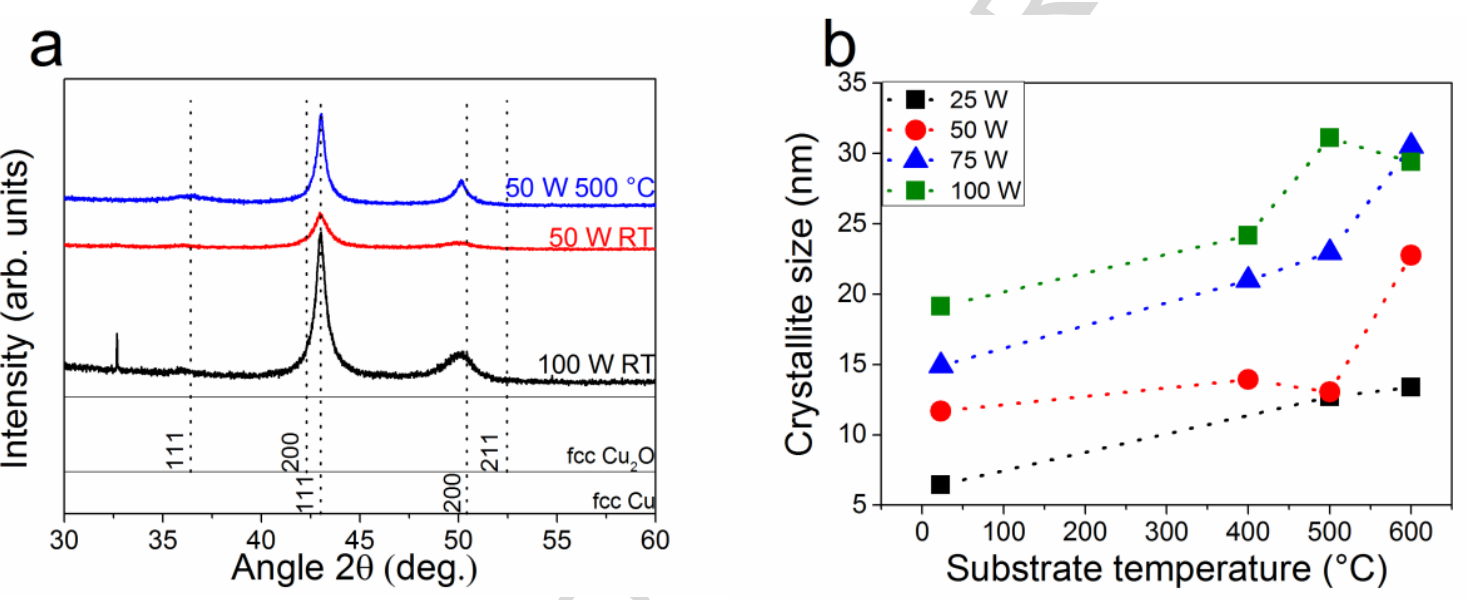

Figure 4: (a) XRD patterns recorded on $\mathrm{nc}-\mathrm{Cu} / \mathrm{C}$ films deposited for 3 deposition conditions $\left(\mathrm{P}_{\mathrm{Cu}}=50 \mathrm{~W}\right.$ at room temperature and $\left.500{ }^{\circ} \mathrm{C}, \mathrm{P}_{\mathrm{Cu}}=100 \mathrm{~W}\right)$. (b) Evolution of the $\mathrm{Cu}$ crystallite size for different values of $\mathrm{P}_{\mathrm{Cu}}$, deduced from the (111) peak, as a function of the deposition temperature. 


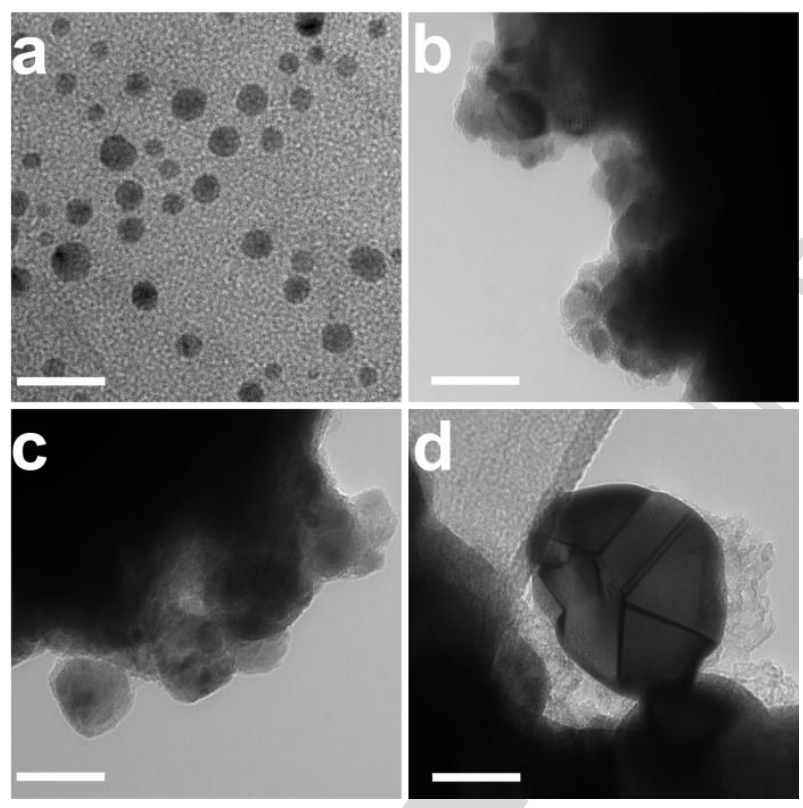

Figure 5: Transmission electron microscopy images of $\mathrm{nc}-\mathrm{Cu} / \mathrm{C}$ films for $\mathrm{P}_{\mathrm{Cu}}=75 \mathrm{~W}$ with different substrate temperatures: $\mathrm{RT}(\mathrm{a}), 400{ }^{\circ} \mathrm{C}$ (b), $500{ }^{\circ} \mathrm{C}$ (c) and $600{ }^{\circ} \mathrm{C}$ (d) (scale bar: 20 $\mathrm{nm})$ 

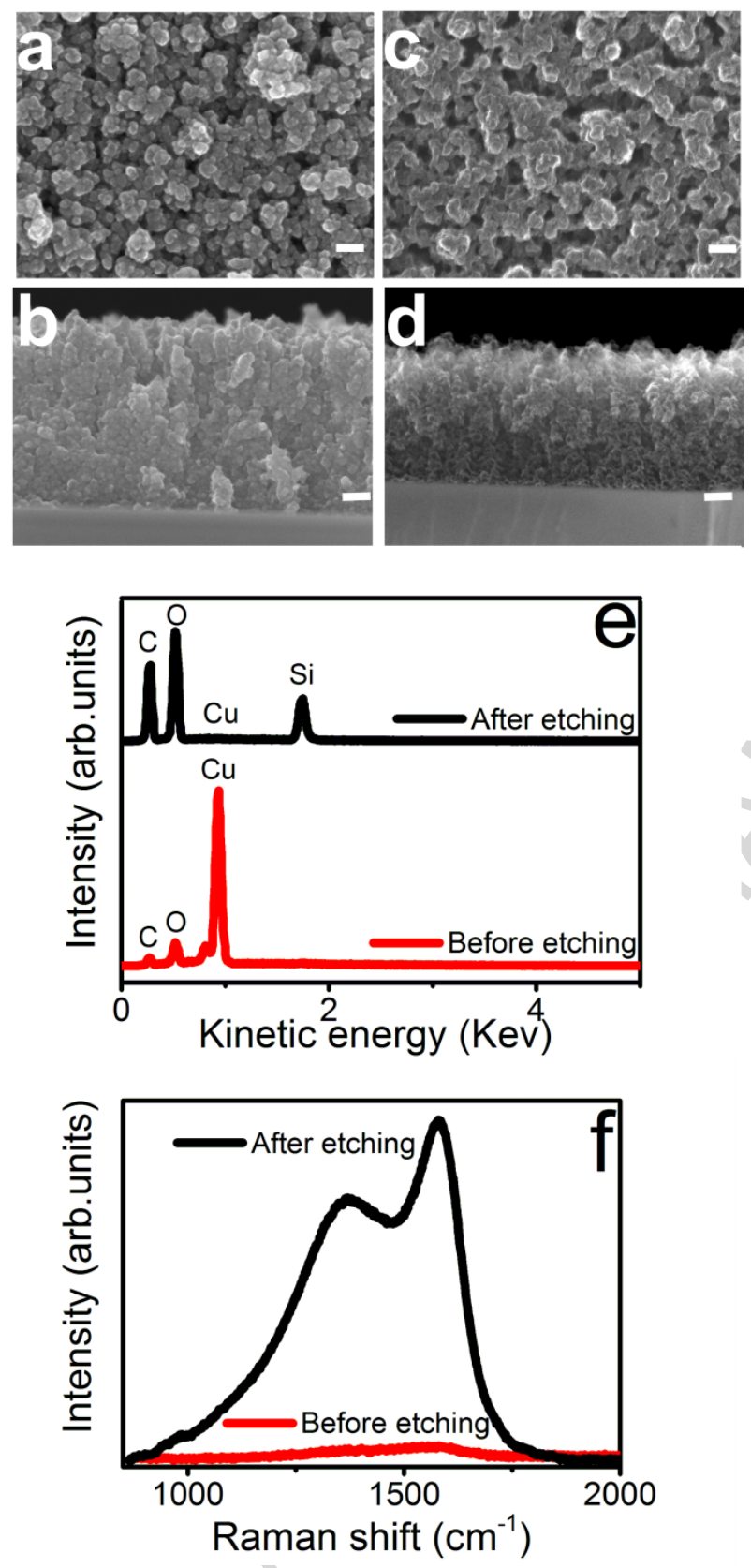

Figure 6: Plan-view and cross-sectional SEM micrographs (Scale bar $100 \mathrm{~nm}$ ) recorded on nc-Cu/C films grown with $\mathrm{P}_{\mathrm{Cu}}=50 \mathrm{~W}$ at $400{ }^{\circ} \mathrm{C}$ before ( $\mathrm{a}$ and $\mathrm{b}$ ) and after etching ( $\mathrm{c}$ and $\mathrm{d}$ ). EDS spectrum to verify the disappearance of copper after etching (e). Raman spectrum before and after etching (f). 

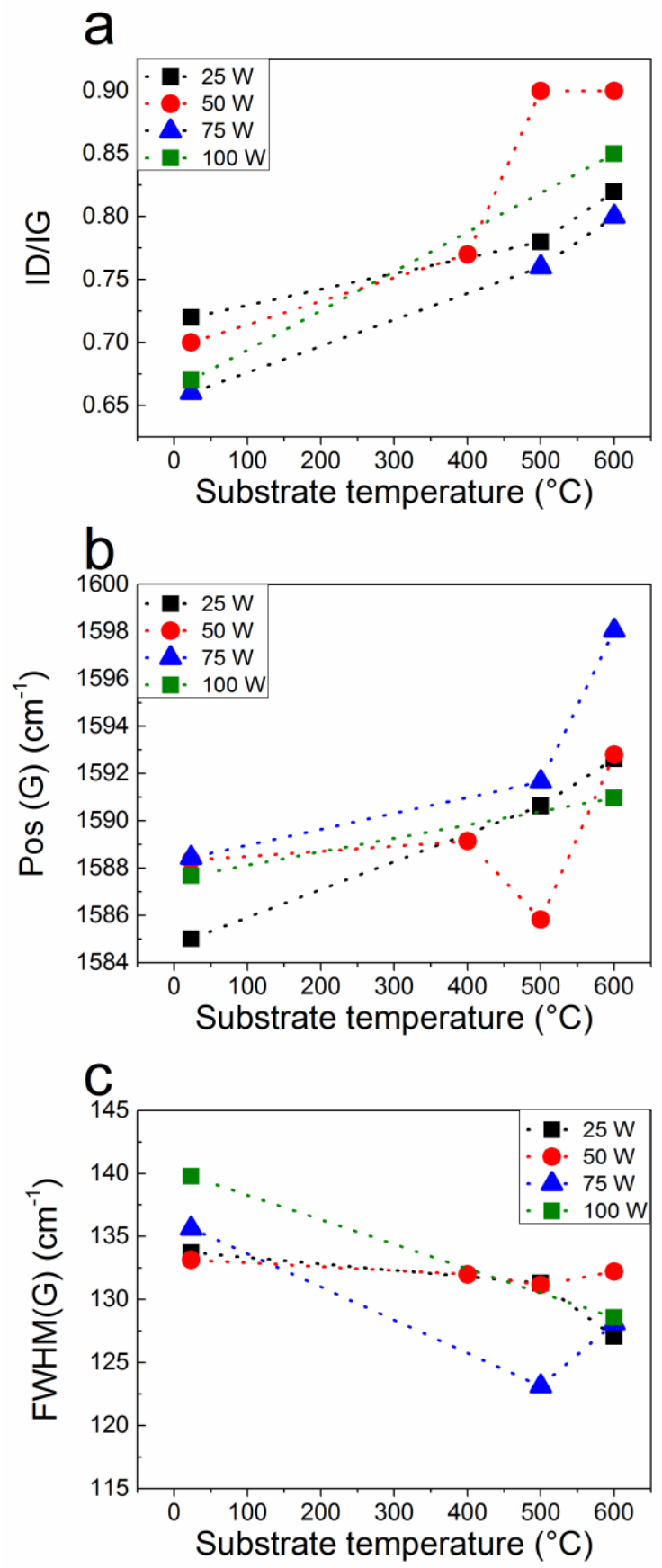

Figure 7: Evolution of the Raman parameters as a function of the deposition temperature (ranging from $\mathrm{RT}$ to $600{ }^{\circ} \mathrm{C}$ ): (a) $\mathrm{I}_{\mathrm{D}} / \mathrm{I}_{\mathrm{G}}$ ratio, (b) Pos $(\mathrm{G})$ and $\mathrm{FWHM}(\mathrm{G})$ for the different deposited conditions $\left(\mathrm{P}_{\mathrm{Cu}}=25,50,75\right.$ and $\left.100 \mathrm{~W}\right)$. 

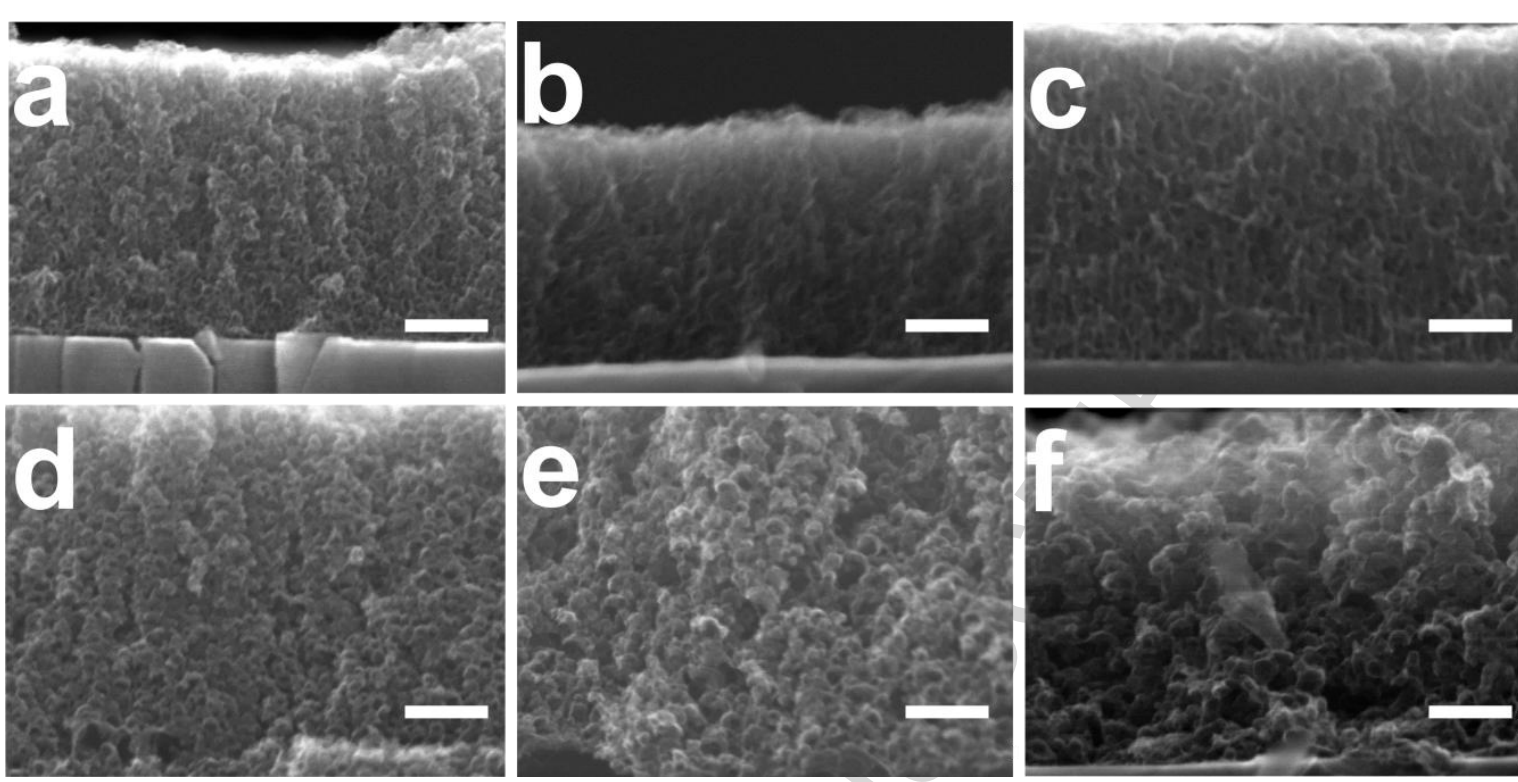

Figure 8: Cross-section SEM images of nanoporous carbon from $\mathrm{nc}-\mathrm{Cu} / \mathrm{C}$ thin film grown at room temperature (a-c) and at $500{ }^{\circ} \mathrm{C}$ (d-f) with different values of $\mathrm{P}_{\mathrm{Cu}}: 25 \mathrm{~W}$ (a and d), $50 \mathrm{~W}$ (b and e), $75 \mathrm{~W}$ (c and f) (Scale bar $100 \mathrm{~nm}$ ) 


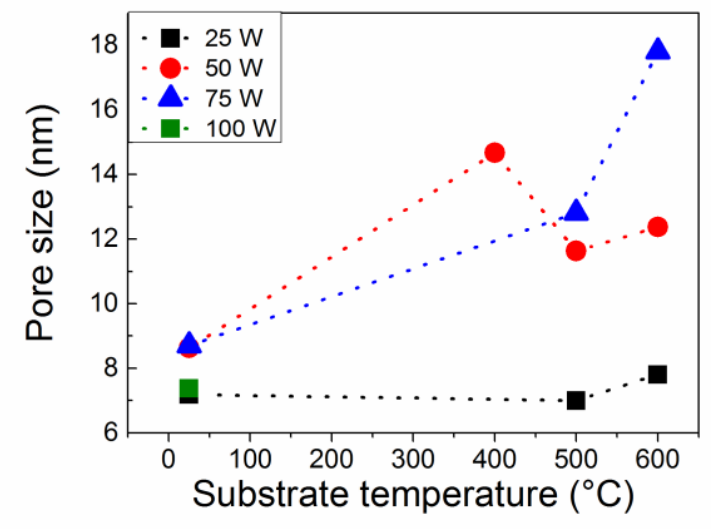

Figure 9: Evolution of the nanoporous carbon pore size estimated from SEM images at very high magnification (X250 000) as a function of the deposition temperature for different values of $\mathrm{P}_{\mathrm{Cu}}(25 \mathrm{~W}$ to $100 \mathrm{~W})$. 

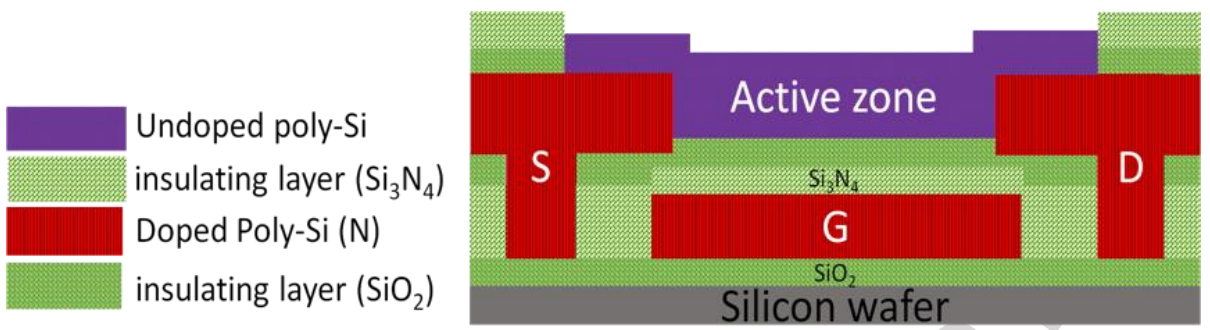

Figure 10: Cross-section layout of bottom gate field effect transistor, S: Source, D: Drain and G: Gate. 

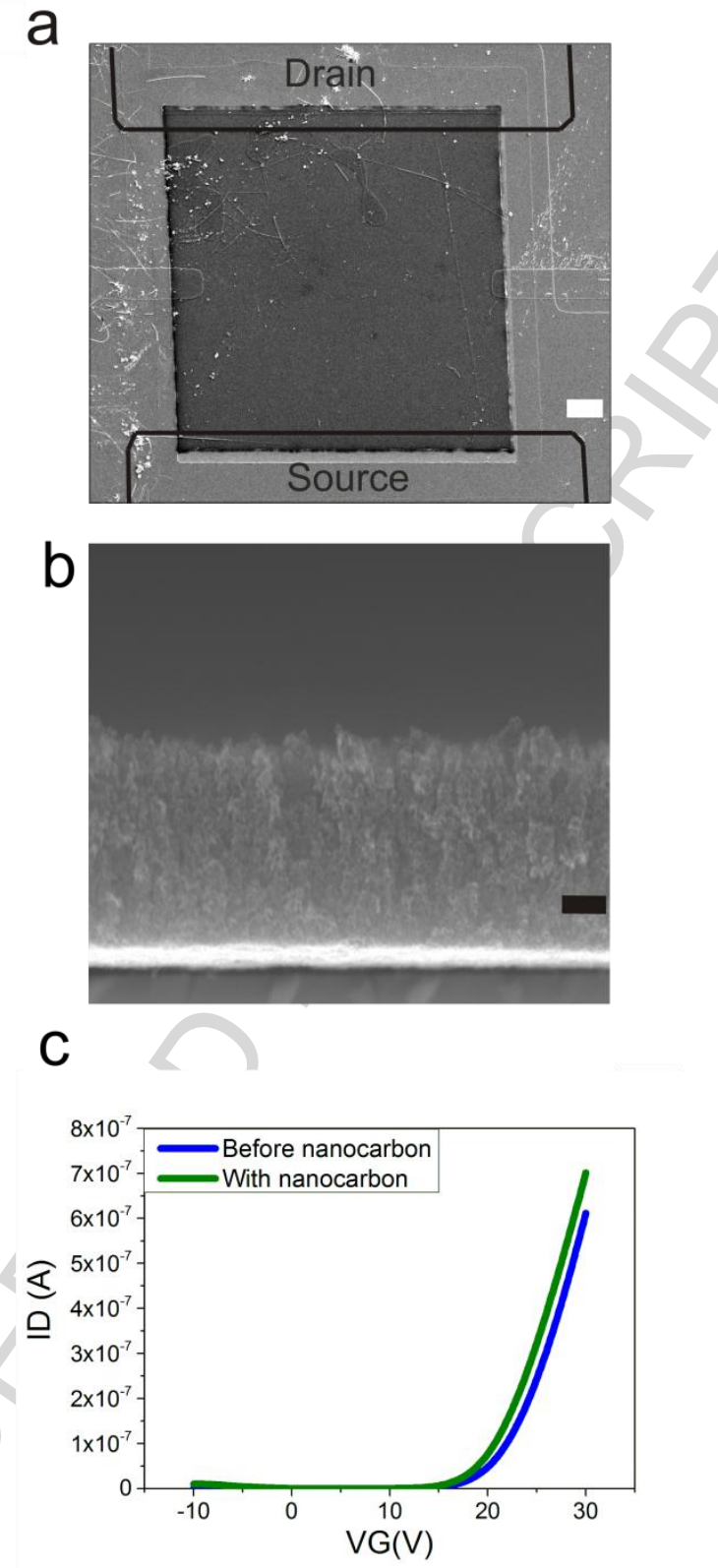

Figure 11: (a) SEM top view of the MOSFET with source, drain zones and naporous carbon layer deposited on the active region surface (with scale bar $20 \mu \mathrm{m}$ ). (b) SEM cross section of nanoporous carbon layer at the surface of the transistor (black scale bar $200 \mathrm{~nm}$ ). Transfer characteristics before and after deposition of the nanocarbon layer (c). 
Highlights

Nanoporous carbon layer are synthesized using nc-Cu/C films by magnetron sputtering.

Effect of $\mathrm{Cu} / \mathrm{C}$ composition and deposition temperature are studied.

Nanoporous pore size and carbon microstructure can be controlled.

Integration of nanoporous carbon on MOSFET for sensing application is demonstrated. 